\title{
Cascading effects of predator richness
}

\author{
John F Bruno $^{1^{*}}$ and Bradley J Cardinale ${ }^{2}$
}

Biologists have long known that predators play a key role in structuring ecological communities, but recent
research suggests that predator richness - the number of genotypes, species, and functional groups that com-
prise predator assemblages - can also have cascading effects on communities and ecosystem properties.
Changes in predator richness, including the decreases resulting from extinctions and the increases resulting
from exotic invasions, can alter the composition, diversity, and population dynamics of lower trophic levels.
However, the magnitude and direction of these effects are highly variable and depend on environmental con-
text and natural history, and so are difficult to predict. This is because species at higher trophic levels exhibit
many indirect, non-additive, and behavioral interactions. The next steps in predator biodiversity research will
be to increase experimental realism and to incorporate current knowledge about the functional role of preda-
tor richness into ecosystem management.

Front Ecol Environ 2008; 6, doi:10.1890/070136

W e know that predators play a vital role in maintaining the structure and stability of communities and that their removal can have a variety of cascading, indirect effects (Terborgh et al. 2001; Duffy 2003; Figure 1). But how important is predator richness? Are the numbers of predator genotypes, species, and functional groups ecologically important properties of predator assemblages? Ecologists have recently begun to address this question by exploring the many potential links between predator richness and the structure and dynamics of lower trophic levels. The initial phases of research on the effects of biodiversity on ecosystem functioning (BEF) focused almost exclusively on single trophic level systems comprised primarily of terrestrial plants. While these studies formalized and explored the idea that biodiversity can regulate key properties of communities and ecosystems, there is a growing belief that the failure to incorporate consumers into $\mathrm{BEF}$ research has led to overly simplistic conclusions (Paine 2002). Ecologists have therefore begun to explore

\section{In a nutshell:}

- Predator richness is rapidly changing in many ecosystems due to predator extinctions and exotic invasions

- Recent experiments indicate that changes in predator richness can have either positive or negative effects on a given ecosystem function or property, depending on the biological traits of predators and their prey, habitat characteristics, and environmental conditions

- Given this uncertainty, caution is warranted when formulating management plans based on the premise that increasing predator richness will broadly enhance the functioning or stability of ecosystems

${ }^{1}$ Department of Marine Sciences, The University of North Carolina at Chapel Hill, Chapel Hill, NC 27599 *(jbruno@unc.edu); ${ }^{2}$ Department of Ecology, Evolution, and Marine Biology, University of California at Santa Barbara, Santa Barbara, CA 93106 the effects of changing biological richness at higher trophic levels, and BEF research is rapidly expanding into a more realistic, multi-trophic context (Duffy et al. 2007).

Here, we review the emerging field of predator biodiversity research, as well as the underlying mechanisms through which predator richness can affect lower trophic levels and ecosystem properties. We then consider how to apply lessons learned from theoretical and experimental predator richness studies to habitat and ecosystem conservation and management.

\section{Native extinctions, exotic invasions, and trophic skew}

A primary rationale for studying the effects of predator richness is that habitat alteration and loss and harvesting for sustenance, profit, and sport have led to substantial declines in the richness of top predators in a wide variety of habitats (Ricciardi and Rasmussen 1999; Terborgh et al. 2001). In most natural food webs, richness tends to be lower at top trophic levels (Petchey et al. 2004). Furthermore, predators, particularly large vertebrates, tend to have a disproportionately high probability of extinction (Figure 2a). This is due, at least in part, to their small population sizes and long generation times, which can increase vulnerability to environmental change (Tracy and George 1992; McKinney 1997). The disproportionate loss of predators can lead to a phenomenon called "trophic skew", or a shift in the ratio of the number of species between consumer and prey trophic levels (Duffy 2003; Byrnes et al. 2007). Because predation intensity is thought to be influenced by the ratio of richness between adjacent trophic levels (Hillebrand and Cardinale 2004), trophic skew has the potential to fundamentally alter the structure and dynamics of food webs.

Predator extinctions rarely happen in isolation. They are nearly always accompanied by the inclusion of new 

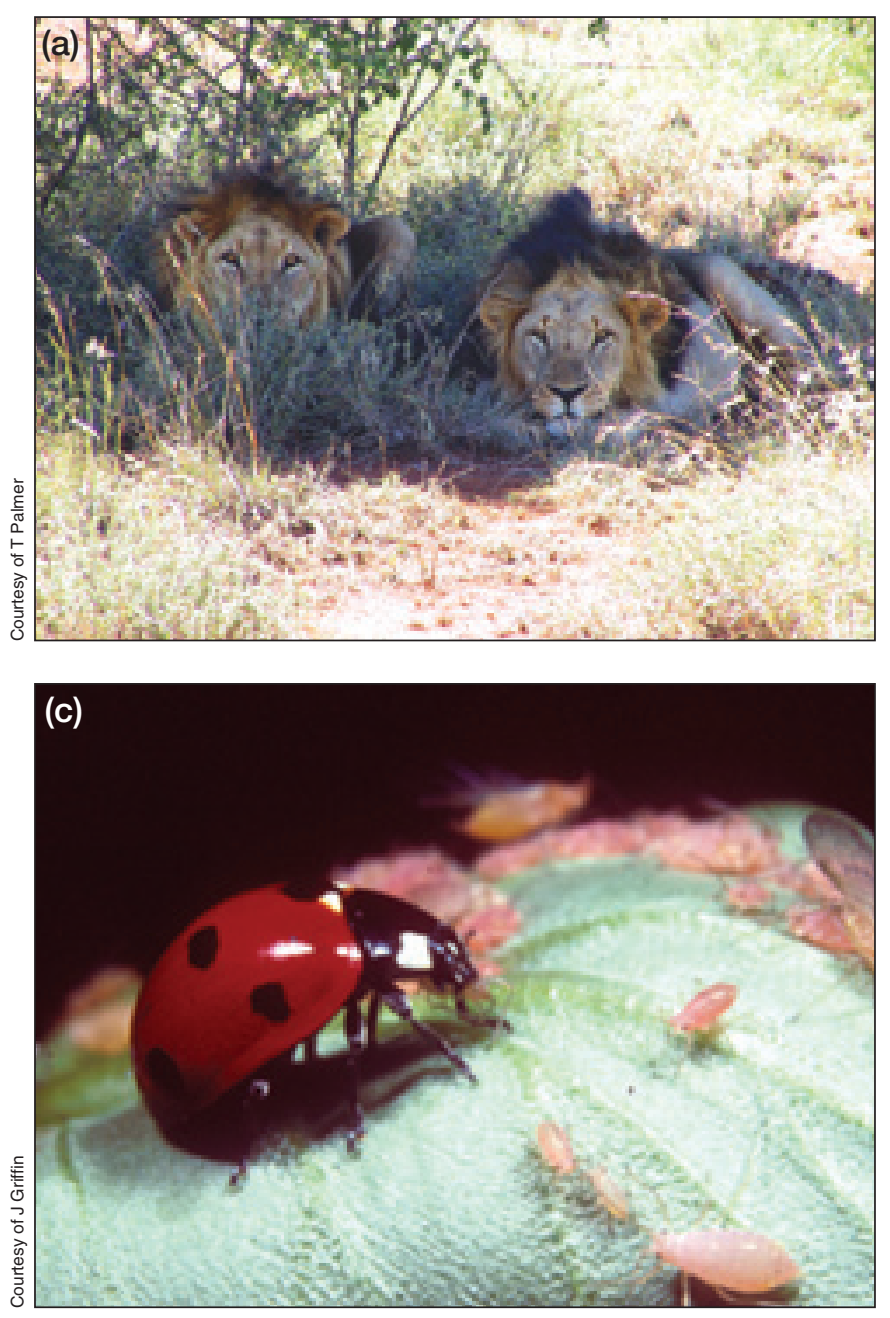

exotic predators as well as deletions and additions of species at other trophic levels (Byrnes et al. 2007). In some systems, species introductions have outpaced native extinctions, leading to a net increase in local richness (Sax and Gaines 2003). For example, in some streams and lakes, the addition of exotic fish - often purposeful (Eby et al. 2006) - has increased total predator richness quite dramatically (Gido and Brown 1999; Sax and Gaines 2003). But this is not always the case. In San Francisco Bay, there are very few exotic predators and a large number of invasions by primary consumers, such as macroplanktivores and detritivores (Figure $2 \mathrm{~b}$ ). In contrast, in the Chesapeake Bay estuarine ecosystem, invasions by predators and plants have outpaced the addition of exotic herbivores, thereby increasing the carnivore-toherbivore richness ratio and decreasing the herbivore-toprimary producer ratio (Figure 2c). A key ecological question is whether such changes to the topology of food webs will lead to altered rates of energy flow and biomass distribution among trophic levels.

\section{- Current evidence for predator richness effects}

Of the more than $150 \mathrm{BEF}$ experiments that have been performed over the past decade, 16 directly manipulated

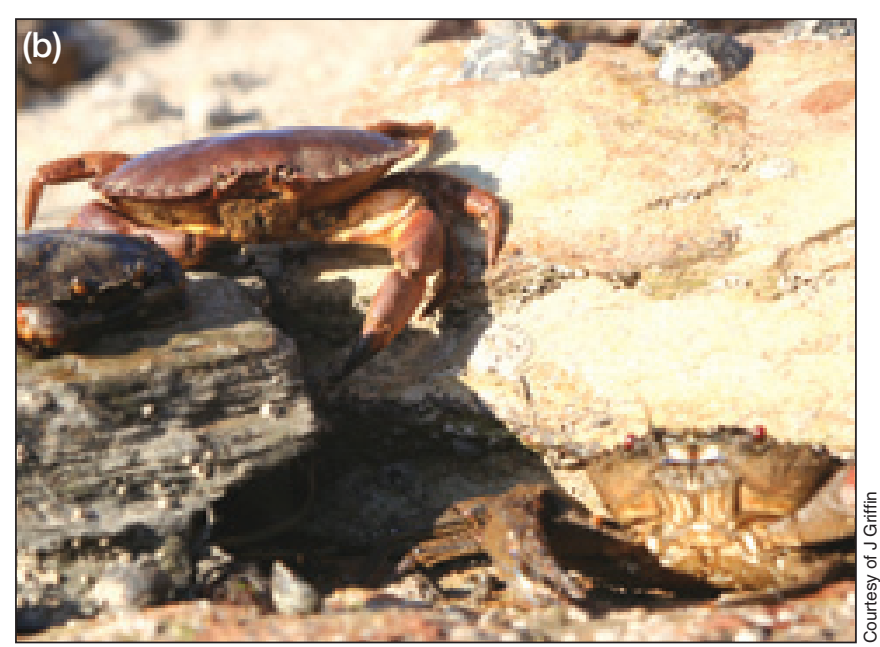

Figure 1. (a) Lions on the Serengeti. (b) Crabs are important predators in rocky intertidal communities. These three species, (clockwise from top left) Carcinus maenas, Cancer pagurus, and Necora puber, have slightly different diets, causing overall prey consumption to increase when all three predators are present (Griffin et al. in press). (c) Ladybird beetles are common predators of aphids, which are among the most commercially important pests worldwide. Here, Coccinella septempunctata is seen feeding on the pea aphid, Acyrthosiphon pisum.

the richness of predators (Cardinale et al. 2006a). Although there are still too few studies to draw broad generalizations, several trends are worth noting. First, decreases in predator richness generally led to a reduction in the combined density of predators (Figure 3). Furthermore, in roughly $40 \%$ of experiments, reductions in predator richness also led to increased densities of prey (Figure 3). However, resource managers often care less about the average effect of predator richness and more about whether a diverse predator assemblage can outperform the single most effective predator species (eg farmers interested in maximizing pest control). With regard to research on the latter, the results are mixed. Five of 14 experiments indicate that diverse predator assemblages suppress prey populations to a greater degree than single predator species (Figure 3 ). The other nine studies found that prey densities in diverse predator assemblages were not different, or lower than the single most effective predator.

Clearly, the studies performed to date have revealed considerable variability in the nature (ie the magnitude and direction) of predator richness effects. This variability is far greater than that typically observed in studies of plant richness, which usually find that decreasing richness leads to lower production of plant biomass and lower rates of nutrient uptake (Cardinale et al. 2006a). Perhaps this difference should have been anticipated, since the effects of predator richness are not necessarily mediated by the same mechanisms as those of plant biodiversity (Duffy 2002; Ives et al. 2005; Long et al. 2007). Ecological theory suggests that 


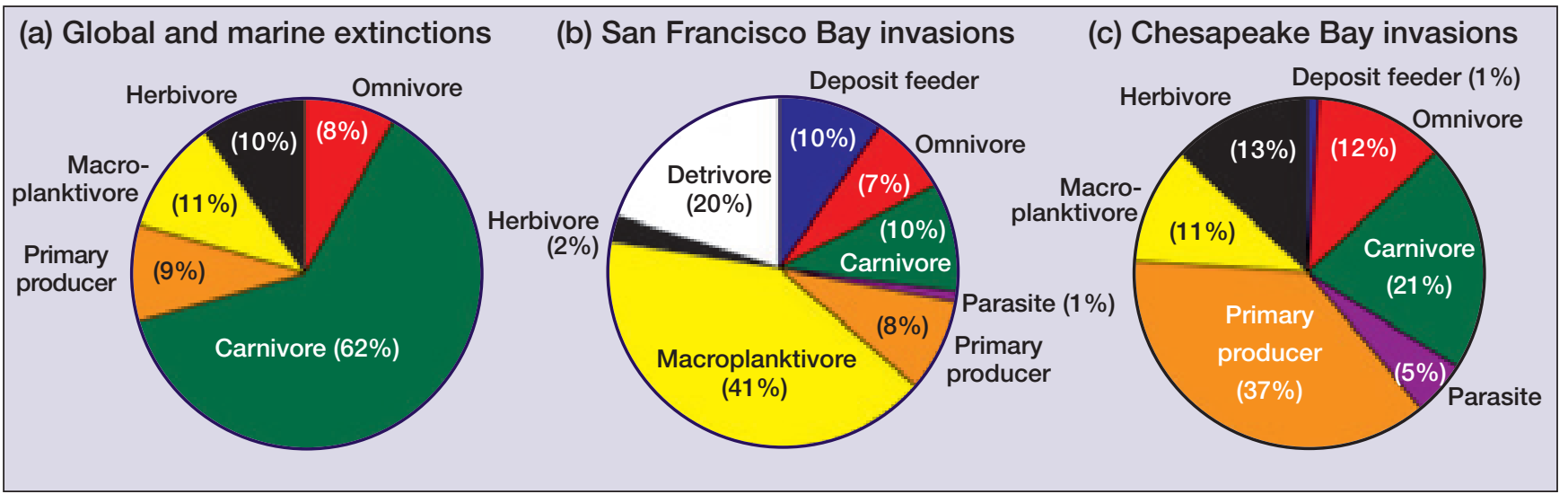

Figure 2. (a) Percentage of global and regional extinctions of marine species in different trophic categories (redrawn from Byrnes et al. 2007). ( $b$ and c) The percentage of exotic species currently found in two North American estuaries in different trophic categories. In both cases, exotic herbivores are relatively uncommon and, in San Francisco Bay, there are few exotic top predators or primary producers (redrawn from Byrnes et al. 2007). The Chesapeake Bay figure is derived from a database of 230 exotic species compiled by the Smithsonian Environmental Research Center.

resource partitioning and selection effects tend to be the dominant mechanisms (or categories of mechanisms) underlying richness effects at all trophic levels (Ives et al. 2005; Casula et al. 2006). But a wide range of other phenomena based on non-additive and indirect species interactions, some of which are rare among plants but are common among predators, have powerful effects on food-web dynamics (Polis and Holt 1992; Sih et al. 1998). This suite of additional interactions and complex behavioral responses appear to play a dominant role in controlling the responses of ecosystem functioning to changes in predator richness.

\section{Resource partitioning}

Different predator species or functional groups often consume different prey species (Duffy 2002; Sinclair et al. 2003) or different life-history stages of a single prey species (Wilby et al. 2005). Different predators also frequently feed in different habitats within an ecosystem or during different times of the day (Murdoch and Briggs 1996). Such resource partitioning (also called dietary complementarity) is thought to be common among organisms and is even viewed as one of the primary means by which species co-exist in nature (Tilman 1982; Chesson 2000). It is also typically assumed that resource partitioning will cause the combined biomass or density of consumers to increase, and the biomass or density of the shared resource(s) to decrease, as consumer richness increases (Tilman et al. 1997). However, mathematical theory (Loreau 2004; Ives et al. 2005) suggests that a number of qualitatively distinct relationships are possible, and the relationship between predator richness and prey density depends greatly on the extent of prey overlap exhibited by different predator species (Figure 4).

To date, empirical research has yet to determine which of the qualitatively plausible relationships are most common in nature. In fact, there is currently little direct experimental evidence that predator richness even influences prey capture via resource partitioning, although some recent mesocosm experiments are somewhat supportive of this hypothesis (eg Griffin et al. in press). This may be due, entirely or in part, to the logistical difficulties of documenting the niches used by different predator species. Also, most predator richness experiments have used either a single herbivore or plant species, thus creating unusual inverted experimental food webs (greater numbers of species at higher trophic levels) that may preclude resource partitioning from occurring in the first place (Griffin et al. in press).

\section{Selection effects}

Selection effects occur when richness increases the chance that species with strong or unique impacts on a process will dominate the functions performed by a community. This might occur if, for example, richness increases the chance that keystone predators, facilitators, or predators with high per capita impacts on prey are included in a natural or experimental food web. Selection effects generally cause the capture and consumption of limited resources to increase as a function of predator richness (Figure 4). However, selection effects may either increase or decrease the total density of predators, depending on whether predator species differ in their rates of prey capture or assimilation efficiencies (Ives et al. 2005).

The selection effect was a controversial mechanism when BEF research first began, with some ecologists arguing that it was nothing more than a statistical artifact of studies that use random draws of species to create experimental communities (ie a probabilistic inevitability; Huston 1997). However, this interpretation has since been shown to be incorrect. Mathematical (Cardinale et al. 2004) and empirical (Weis et al. 2007) studies have both demonstrated that the simple probability of including a species in a community cannot, by itself, generate any relationship between species richness and ecosystem functioning. Indeed, the selection effect occurs only 


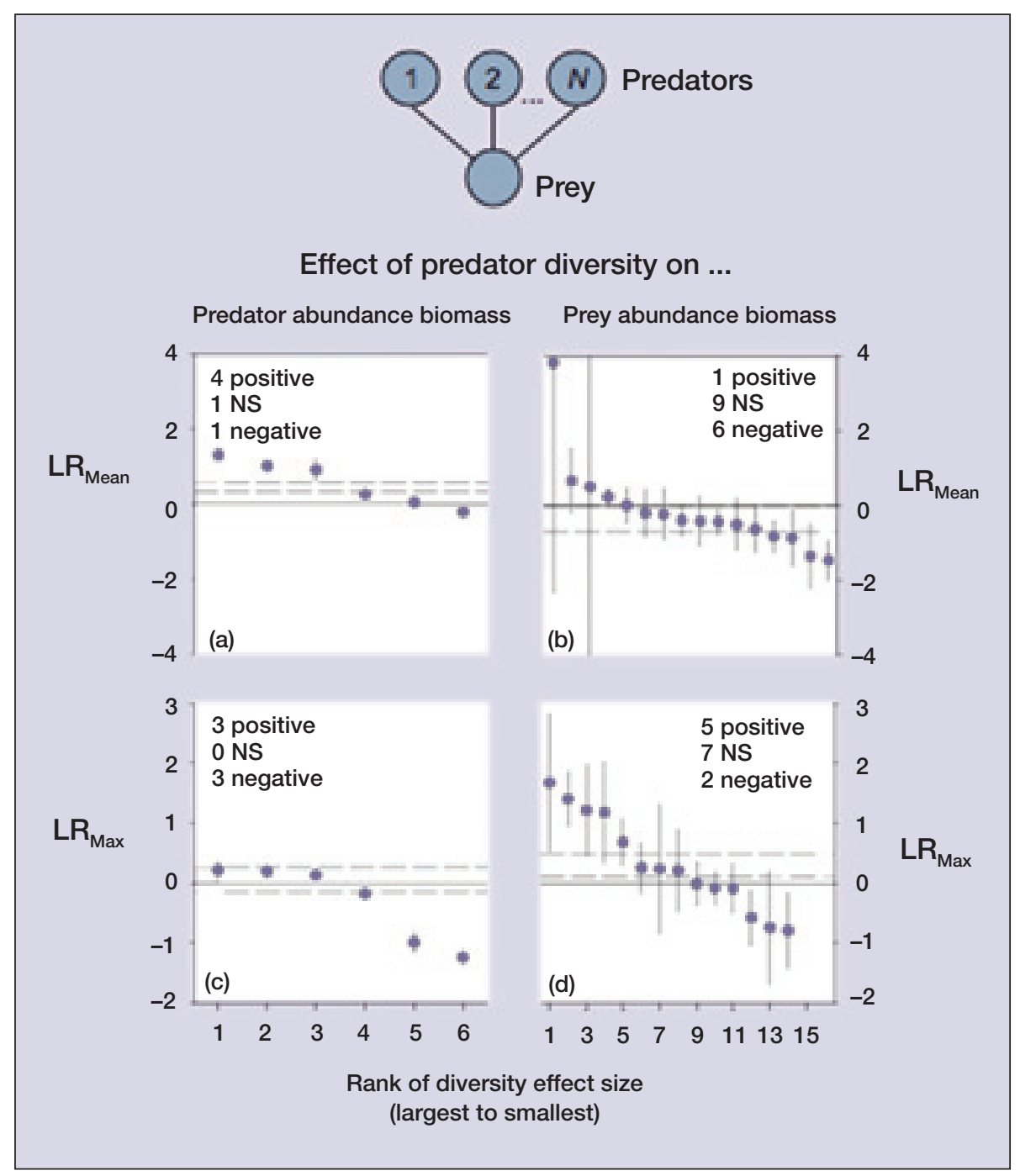

Figure 3. A summary of the results of experiments that have manipulated the richness of predators to examine impacts on predator and prey density (Cardinale et al. 2006a). Log ratios (LR) are the proportional difference between predator or prey densities (abundance or biomass) in the most diverse predator assemblages and: ( $a$ and $b$ ) the average predator species when alone in monoculture $\left(L R_{\text {mean }}\right)$ and (c and d) predator species having the highest values when alone in monoculture $\left(L R_{\max }\right)$. Each data point is the mean richness effect size for all replicates in an experiment $\pm 95 \%$ CI. Dashed horizontal gray lines give the $95 \%$ CI for all experiments combined. The experiments summarized here range from laboratory studies of aquatic protozoans that prey on bacteria to field experiments on natural enemies that attack insect pests in agricultural ecosystems. The average experiment manipulated the richness of just four predator species (range $=$ three to six) for less than one generation (range $=0.005$ to 57 ) in relatively small micro- or mesocosms (range $=0.4$ to $4 \mathrm{~m}^{2}$ for terrestrial or 0.02 to $400 \mathrm{~L}$ for aquatic).

when distinct biological interactions, such as competition or facilitation, alter the performance of species interacting in a diverse community relative to their performance when alone in monoculture.

Just as there is scant direct evidence for resource partitioning, rigorous empirical demonstrations of selection effects for predators are rare. In part, this is because the statistical techniques used to detect selection effects in plant communities require measures of the performance of each individual species in polyculture. Such measure- ments (eg prey capture by each predator species in polyculture) are often laborious or impossible to obtain in predator studies. Even so, studies have used alternative means to suggest that the impacts of predator richness are driven by the contributions of individual species (Bruno and O'Connor 2005; Straub and Snyder 2006). Such results are consistent with patterns reported in non-experimental studies. For example, Denoth et al. (2002) reviewed the results of 108 biological control projects where predators, parasites, or pathogens were released to control insect pests. They concluded that, although the success of biological control frequently increased with the number of agents released, a single species was responsible for the success of control in more than half of all successful projects.

\section{Other mechanisms: non- additive and indirect species interactions}

There are a variety of additional biological phenomena, some unique to predators, that can lead to or modify predator richness effects. Most are based on non-additive or indirect species interactions - which are categories of mechanisms rather than discrete mechanisms themselves - and in many cases on both (the ecological mechanisms that occur within multi-species predator-prey communities rarely fit neatly into these or other tidy categories). Non-additive species interactions are interactions that cause a multi-predator assemblage to perform differently than the "sum of its parts". Sometimes called emergent multi-predator effects (Sih et al. 1998), these effects can arise when synergistic interactions such as predator-predator facilitation, or antagonisms such as interference competition, cause per capita prey capture by a predator to change in the presence of other predator species (Sih et al. 1998; Bruno et al. 2003).

Many examples of non-additive interactions exist, but most are based on studies of systems composed of just two predator species. Even so, these have produced a number of excellent case studies that illustrate the potential com- 
plexity of predator richness effects. For example, as foliar predators like ladybeetles search for their aphid prey, the aphids detect vibrations from the oncoming predator and drop from the plant onto the ground (Losey and Denno 1998). This increases susceptibility to ground predators. such as carabid beetles. Thus, ladybeetles indirectly facilitate prey capture by ground beetles and, somewhat paradoxically, the escape behavior of the aphid is what causes the predator polyculture to capture more total aphids than either monoculture.

There are also numerous examples of non-additive and indirect predator effects that can reduce prey suppression as predator richness increases. For example, Crowder et al. (1997) measured the consumption of estuarine fish by predatory flounder and birds in experimental ponds. Surprisingly, combining the two predators increased prey survival, compared to single predator treatments. This nonadditive effect was caused by either a negative effect of birds on flounder or a prey behavioral response to birds (eg aggregation) that also reduced predation by flounder (Crowder et al. 1997).

Omnivory and intra-guild predation are widespread interactions among species (Polis and Holt 1992; VanceChalcraft et al. 2007) that lead to numerous indirect effects (many of which are also non-additive) of predators on prey across multiple trophic levels (Figure 4). The complex behaviors exhibited by many animals can also modify predator richness effects by decoupling the impacts on prey from predator densities or per capita interaction strengths (Finke and Denno 2005). For example, herbivores often reduce their foraging activity or shift foraging efforts to different habitats or times to avoid predators, leading, in turn, to reductions in herbivory (Trussell et al. 2003).

To make matters even more complex, omnivory and intra-guild predation can lead to both positive and negative relationships between predator richness and herbivore density or plant production (Figure 4). For instance, Finke and Denno (2005) found that increasing spider predator richness in salt marsh food webs decreased the strength of trophic cascades. Due to intra-guild predation, and possibly also to non-lethal interactions among predators, herbivore population suppression was reduced at high levels of predator richness, also leading to reduced primary production. Similarly, Bruno and O'Connor (2005) found that, in subtidal marine communities, the inclusion of omnivores in high-richness assemblages tended to reduce both plant and herbivore abundance.

While experiments clearly show that predator richness can influence the strength of trophic cascades by modifying indirect interactions, a central challenge of future BEF research is to identify the traits of predators and their prey that influence the direction of these effects (Schmitz 2007). A recent review of predator richness experiments revealed that, in most cases, increasing predator richness actually reduced the primary direct ecosystem function performed by predators (ie consuming prey and controlling their populations; Schmitz 2007). This was not due to inadequate experimental realism, since a much greater proportion $(71 \%)$ of larger and more realistic field experiments documented such negative effects of predator richness on functioning than did smaller-scale laboratory studies (30\%). In fact, only $7 \%$ of published field experiments actually support the paradigm that increasing predator richness increases prey consumption (Schmitz 2007). Thus, despite frequent claims to the contrary, synergisms among predators may be rare or weak compared to non-additive antagonisms. Unfortunately, Schmitz's meta-analysis obscures the distinction between mechanisms that operate through changes in combined predator density (ie resource partitioning) versus mechanisms that operate through changes in per capita predator 
effects (ie non-additivity). Thus, the question of whether non-additive interactions generally enhance or reduce prey capture, predator biomass, and the other functions performed by predators remains unresolved.

\section{Socioeconomic impacts of predator richness}

To date, only a handful of studies have explored the socioeconomic impacts of predator richness, and even then, only indirectly. Most examples derive from agricultural ecosystems and focus on the effects of predator richness on the biological control of insect pests (Figure 1c), currently valued at $\$ 4.49$ billion per year in the US (Losey and Vaughan 2006) and >US $\$ 400$ billion per year globally (Costanza et al. 1997). For example, Cardinale et al. (2003) manipulated the richness of three natural enemies of pea and cowpea aphids that consume alfalfa. Two of these enemies - a species of ladybeetle and the assassin bug - were generalist predators that feed on both aphid species. The third was a specialist parasitoid wasp that attacks only pea aphids. As generalist predators reduced the density of both types of aphids, the parasitoid wasp became more efficient at attacking the pea aphid. As a result, when the three predators co-occurred, they reduced aphid populations to one-half of that achieved by single enemy species alone and doubled alfalfa yield.

Although other studies also indicate that predator richness can enhance pest control (Wilby et al. 2005), there are a number of counterexamples. A follow-up experiment in an alfalfa-aphid system by the same research group used three species of ladybeetles and found that, when combined, these generalist predators competed intensely, greatly reducing prey capture efficiency and ultimately decreasing alfalfa yield by $17 \%$ (Cardinale et al. 2006b). This result underscores an ongoing debate about the possibility that high predator richness might actually reduce biological control of pests by promoting antagonistic interactions among predator species that impede capture efficiency (Rosenheim et al. 1995; Murdoch and Briggs 1996). Thus, despite the enormous value of this ecosystem service (eg the estimated annual value of the US alfalfa crop is $\$ 11.7$ billion, US Department of Agriculture), biologists are not yet in a position to predict whether changes in predator richness will generally increase or decrease these and other ecosystems services.

\section{Implications for management and conservation}

In the past, the conservation of predators, particularly large vertebrate carnivores, had been justified on a variety of ethical, aesthetic, and socioeconomic grounds. More recently, ecologists have begun to argue that the conservation of predator richness would broadly enhance ecological functioning and services (Worm et al. 2006). It has become increasingly clear over the past decade that changes to the richness of predator species will, in one way or another, fundamentally alter the way that ecosystems function. Preserving or restoring predator species richness is therefore likely to be a necessary condition if we expect to maintain the "natural" state of an ecosystem. However, there is currently little scientific evidence to support the idea that the conservation of predator biodiversity will broadly enhance ecosystem functioning. Management recommendations based on this premise (eg Worm et al. 2006) will inevitably lead to unexpected, and sometimes unfavorable, outcomes.

The handful of rigorous predator richness experiments performed to date have produced mixed results (a point underscored by the titles of two recent papers; Predator richness strengthens trophic cascades... [Byrnes et al. 2006] and Predator richness dampens trophic cascades [Finke and Denno 2004]). Furthermore, as we have emphasized above, several theoretically sound arguments make entirely opposing predictions about the functional role that predator richness plays in ecosystems, depending on the biological traits of the predator species and how they interact with other species in food webs (Figure 4). Thus, given the current state of our knowledge, it is nearly impossible to predict the ecological consequences of predator invasions or extinctions a priori.

The difficulties of prediction may ultimately be overcome as future studies incorporate the biological and environmental contingencies that likely influence predator richness effects. For example, an important and often overlooked characteristic is the complexity and spatial arrangement of habitats, both of which can influence predator-prey interactions (Dambacher et al. 1999). Such landscape features almost certainly modify real-world predator richness effects (Figure 5), although incorporating them into experimental designs will be challenging. Furthermore, some predator richness experiments have been performed in essentially featureless containers (eg Byrnes et al. 2006) or homogeneous landscapes (eg Cardinale et al. 2003), which could lead to unnatural predator and prey behavior and predator richness effects that might not occur in a more natural setting.

Performing more realistic BEF experiments should increase the accuracy of our insights (Figure 5), but even then, management strategies focused on conserving predator richness will face an even more challenging dilemma due to the opposing effects of increasing richness on adjacent trophic levels. These opposing effects make it very unlikely that the conservation of predator richness will be viewed as universally "good" for the wide variety of products and services that are taken from ecosystems. For example, in some systems (eg kelp forests), high plant biomass is valued, but in other systems (eg tropical coral reefs), macroalgae are considered harmful. If managers were to take a general predator richness paradigm to its logical conclusion, this would require that we reduce predator richness in some habitats while maximizing it in others to achieve locally valued community states. Very similar complications arise from the fact that 
predator richness is expected to have completely opposite impacts on adjacent lower trophic levels. Would "maximal" food web function be based on the production of plants, herbivores, or the predators themselves? There is no entirely objective answer to this question.

\section{Conclusions}

The extension of BEF research into a multitrophic context is an exciting new field that promises to reveal how a key property of food webs might influence ecosystems and the services they provide to humanity. At the same time, this work will provide the broader disciplines of ecology and evolution with fundamental insights into the functional role of food web complexity. Although investigations of predator richness performed to date have consistently shown a variety of cascading effects on lower trophic levels, the direction of these effects is, at the moment, anything but predictable. Ecologists must recognize the complexity involved in understanding the role of predator richness, as well as the contradictory nature of the current theory and evidence, before settling on a general predator richness paradigm that makes broad and overly simplistic prescriptions to solve complex environmental problems.

\section{Acknowledgements}

We thank all the colleagues who have influenced our thinking about biodiversity and predator richness. This work was supported in part by funding from the National Science Foundation (OCE-0327191 and OCE-0623736 to JFB and DEB-0614428 to BJC), the University of North Carolina at Chapel Hill, and the University of California at Santa Barbara.

\section{References}

Bruno JF and O'Connor MI. 2005. Cascading effects of predator diversity and omnivory in a marine food web. Ecol Lett 8: $1048-56$

Bruno JF, Stachowicz JJ, and Bertness MD. 2003. Inclusion of facilitation into ecological theory. Trends Ecol Evol 18: 119-25.

Byrnes J, Stachowicz JJ, Hultgren KM, et al. 2006. Predator diversity strengthens trophic cascades in kelp forests by modifying herbivore behaviour. Ecol Lett 9: 61-71.

Byrnes JE, Reynolds PL, and Stachowicz JJ. 2007. Invasions and extinctions reshape coastal marine food webs. PLoS One 2: e295.

Cardinale BJ, Harvey CT, Gross K, and Ives AR. 2003. Biodiversity and biocontrol: emergent impacts of a multi-enemy assemblage on pest suppression and crop yield in an agroecosystem. Ecol Lett 6: 857-65.

Cardinale BJ, Ives AR, and Inchausti P. 2004. Effects of species diversity on the primary productivity of ecosystems: extending our spatial and temporal scales of inference. Oikos 104: 437-50.

Cardinale BJ, Srivastava DS, Duffy JE, et al. 2006a. Effects of biodiversity on the functioning of trophic groups and ecosystems. Nature 443: 989-92.

Cardinale BJ, Weis JJ, Forbes AE, et al. 2006b. Biodiversity as both a cause and consequence of resource availability: a study of reciprocal causality in a predator-prey system. J Anim Ecol 75: 497-505.

Casula P, Wilby A, and Thomas MB. 2006. Understanding biodiversity effects on prey in multi-enemy systems. Ecol Lett 9: 995-1004.

Chesson P. 2000. Mechanisms of maintenance of species diversity. Annu Rev Ecol Syst 31: 343-66.

Costanza R, d'Arge R, deGroot R, et al. 1997. The value of the world's ecosystem services and natural capital. Nature 387: 253-60.

Crowder LB, Squires DD, and Rice JA. 1997. Nonadditive effects of terrestrial and aquatic predators on juvenile estuarine fish. Ecology 78: 1796-1804.

Dambacher JM, Li HW, Wolff JO, and Rossignol PA. 1999. Parsimonious interpretation of the impact of vegetation, food, and predation on snowshoe hare. Oikos 84: 530-32.

Denoth M, Frid L, and Myers JH. 2002. Multiple agents in biological control: improving the odds? Biol Control 24: 20-30.

Duffy JE. 2002. Biodiversity and ecosystem function: the consumer connection. Oikos 99: 201-19.

Duffy JE. 2003. Biodiversity loss, trophic skew and ecosystem functioning. Ecol Lett 6: 680-87.

Duffy JE, Cardinale BJ, France KE, et al. 2007. The functional role of biodiversity in ecosystems: incorporating trophic complexity. Ecol Lett 10: 522-38.

Eby LA, Roach WJ, Crowder LB, and Stanford JA. 2006. Effects of stocking-up freshwater food webs. Trends Ecol Evol 21: 576-84. 
Finke DL and Denno RF. 2004. Predator diversity dampens trophic cascades. Nature 429: 407-10.

Finke DL and Denno RF. 2005. Predator diversity and the functioning of ecosystems: the role of intraguild predation in dampening trophic cascades. Ecol Lett 8: 1299-1306.

Gido KB and Brown JH. 1999. Invasion of North American drainages by alien fish species. Freshwater Biol 42: 387-99.

Griffin J, de la Haye K, Hawkins S, et al. Predator diversity and ecosystem functioning: density modifies the effect of resource partitioning. Ecology. In press.

Hillebrand $\mathrm{H}$ and Cardinale BJ. 2004. Consumer effects decline with prey diversity. Ecol Lett 7: 192-201.

Huston MA. 1997. Hidden treatments in ecological experiments: re-evaluating the ecosystem function of biodiversity. Oecologia 110: 449-60.

Ives AR, Cardinale BJ, and Snyder WE. 2005. A synthesis of subdisciplines: predator-prey interactions, and biodiversity and ecosystem functioning. Ecol Lett 8: 102-16.

Long ZT, Bruno JF, and Duffy JE. 2007. Biodiversity mediates productivity through different mechanisms at adjacent trophic levels. Ecology 88: 2821-29.

Loreau M. 2004. Does functional redundancy exist? Oikos 104: 606-11.

Losey JE and Denno RF. 1998. Positive predator-predator interactions: enhanced predation rates and synergistic suppression of aphid populations. Ecology 79: 2143-52.

Losey JE and Vaughan M. 2006. The economic value of ecological services provided by insects. BioScience 56: 311-23.

McKinney ML. 1997. Extinction vulnerability and selectivity: combining ecological and paleontological views. Annu Rev Ecol Syst 28: 495-516.

Murdoch WW and Briggs CJ. 1996. Theory for biological control: recent developments. Ecology 77: 2001-13.

Paine RT. 2002. Trophic control of production in a rocky intertidal community. Science 296: 736-39.

Petchey OL, Downing AL, Mittelbach GG, et al. 2004. Species loss and the structure and functioning of multitrophic aquatic systems. Oikos 104: 467-78.

Polis GA and Holt RD. 1992. Intraguild predation - the dynamics of complex trophic interactions. Trends Ecol Evol 7: 151-54.
Ricciardi A and Rasmussen JB. 1999. Extinction rates of North American freshwater fauna. Conserv Biol 13: 1220-22.

Rosenheim JA, Kaya HK, Ehler LE, et al. 1995. Intraguild predation among biological-control agents - theory and evidence. Biol Control 5: 303-35.

Sax DF and Gaines SD. 2003. Species diversity: from global decreases to local increases. Trends Ecol Evol 18: 561-66.

Schmitz OJ. 2007. Predator diversity and trophic interactions. Ecology 88: 2415-26.

Sih A, Englund G, and Wooster D. 1998. Emergent impacts of multiple predators on prey. Trends Ecol Evol 13: 350-55.

Sinclair ARE, Mduma S, and Brashares JS. 2003. Patterns of predation in a diverse predator-prey system. Nature 425: 288-90.

Straub CS and Snyder WE. 2006. Species identity dominates the relationship between predator biodiversity and herbivore suppression. Ecology 87: 277-82.

Terborgh J, Lopez L, Nuñez P, et al. 2001. Ecological meltdown in predator-free forest fragments. Science 294: 1923-26.

Tilman D. 1982. Resource competition and community structure: monographs in population biology. Princeton, NJ: Princeton University Press.

Tilman D, Lehman D, and Thompson K. 1997. Plant diversity and ecosystem productivity: theoretical considerations. P Natl Acad Sci USA 94: 1857-61.

Tracy CR and George TL. 1992. On the determinants of extinction. Am Nat 139: 102-22.

Trussell GC, Ewanchuk PJ, and Bertness MD. 2003. Trait-mediated effects in rocky intertidal food chains: predator risk cues alter prey feeding rates. Ecology 84: 629-40.

Vance-Chalcraft HD, Rosenheim JA, Vonesh JR, et al. 2007. The influence of intraguild predation on prey suppression and prey release: a meta-analysis. Ecology 88: 2689-96.

Weis JJ, Cardinale BJ, Forshay KJ, and Ives AR. 2007. Effects of species diversity on community biomass production change over the course of succession. Ecology 88: 929-39.

Wilby A, Villareal SC, Lan LP, et al. 2005. Functional benefits of predator species diversity depend on prey identity. Ecol Entomol 30: 497-501.

Worm B, Barbier EB, Beaumont N, et al. 2006. Impacts of biodiversity loss on ocean ecosystem services. Science 314: 787-90. 